\title{
Variação dimensional das traqueídes ao longo do caule de Podocarpus lambertii Klotzsch ex Endl., Podocarpaceae
}

\author{
Leila Teresinha Maranho ${ }^{1,3}$, Franklin Galvão², Graciela Inez Bolzon de Muñiz ${ }^{2}$, Yoshiko Saito Kuniyoshi ${ }^{2}$ e \\ Karla Heloise Preussler ${ }^{1}$
}

Recebido em 16/08/2005. Aceito em 9/03/2006

\begin{abstract}
RESUMO - (Variação dimensional das traqueídes ao longo do caule de Podocarpus lambertii Klotzsch ex Endl., Podocarpaceae). O presente estudo foi desenvolvido com o objetivo de avaliar a variação dimensional das traqueídes ao longo do caule de Podocarpus lambertii Klotzsch ex Endl. Discos de madeira de três indivíduos foram retirados em diferentes alturas ao longo do caule. As amostras para o estudo da variação dimensional das traqueídes foram selecionadas no limite das camadas de crescimento e no sentido câmbiomedula. A avaliação do material, assim como sua mensuração e obtenção de imagens foram realizadas utilizando microscopia fotônica (Olympus - BX-41). Os dados obtidos foram analisados estatisticamente. No sentido radial houve um aumento no comprimento das traqueídes em direção medula-câmbio, sendo significativa a diferença entre as camadas de crescimento pela análise do teste "t-student". Houve uma variação mínima no que se refere ao diâmetro das traqueídes e a análise da espessura da parede celular revelou que não houve variação. São apresentadas figuras e tabelas onde são discutidos os resultados obtidos com trabalhos que fazem à mesma abordagem e os fatores que podem influenciar a variação das traqueídes no sentido radial e ao longo da árvore.
\end{abstract}

Palavras-chave: anatomia de madeira, variação dimensional, traqueídes, Podocarpus lambertii, Podocarpaceae

\begin{abstract}
Size variation of tracheids in the stem of Podocarpus lambertii Klotzsch ex Endl., Podocarpaceae). Variation in tracheid size in the stem of Podocarpus lambertii Klotzsch ex Endl. was investigated. Wood samples were taken from three individuals at three different stem heights. From these samples, subsamples were selected at the limit of the growth layers, from the vascular cambium to the medulla. The methodology followed that traditionally recommended for plant anatomy studies. Analyses of the material as well were as the measurements and images were performed by using a light microscopic (Olympus - BX41). In radial section, tracheid length showed a well-defined increase in length from medulla to cambium, which was statistically significant based on the student " $t$ " test. There was minimal variation in tracheid diameter and no variation in cell wall thickness. Results are discussed in relation to factors that may influence variation in tracheids along the tree stem.
\end{abstract}

Key words: wood anatomy, size variation, tracheids, Podocarpus lambertii, Podocarpaceae

\section{Introdução}

Estudos relacionados à estrutura do lenho de diferentes espécies vêm contribuindo cada vez mais para a solução de questões taxonômicas, evolutivas e ecológicas. No que se refere ao aspecto de uso da madeira como fonte de matéria-prima, esses estudos são de grande interesse para pesquisas onde a qualidade da madeira é um dos pontos a ser considerado. De acordo com Silva (1992), a madeira é constituída por elementos xilemáticos e a agregação dos mesmos exibe extrema variabilidade, sendo a maioria uma resposta da árvore ao seu ambiente dentro dos limites do seu potencial genético. Quando se deseja obter uma madeira de boa qualidade é de grande importância que sejam consideradas essas variações. Flörsheim \& Tomazello Filho (1996) e Flörsheim et al. (1999) citam que a variação nas dimensões dos elementos xilemáticos exerce um efeito significativo sobre as propriedades anatômicas das madeiras. Em geral, essas propriedades podem variar dentro e entre árvores e podem interferir significativamente sobre a qualidade da madeira.

Nos últimos anos houve um aumento no número de estudos realizados com o objetivo de buscar uma melhor caracterização das propriedades da madeira por meio da avaliação das células individualmente. Entretanto, a mais de cem anos Sanio (1872) se destaca

\footnotetext{
1 Centro Universitário Positivo, Rua Prof. Pedro Viriato Parigot de Souza 5300, 81280-330 Curitiba, PR, Brasil

2 Universidade Federal do Paraná, Departamento de Ciências Florestais, Rua Lothário Meissner 3400, 80210-170 Jardim Botânico, Curitiba PR, Brasil

3 Autor para correspondência: maranho@unicenp.edu.br
} 
como o pioneiro nessa categoria. Nesse estudo o autor avaliou a dimensão das traqueídes ao longo do caule e ramos de Pinus sylvestris L., porém mesmo se considerado o número relativamente grande de espécies cujo lenho já foi estudado, pode-se dizer que, ainda, este número é pequeno ao se comparar com a biodiversidade de nossa flora.

De acordo com Vysotskaya \& Vaganov (1989), a idade, o vigor, as características genéticas e os fatores climáticos podem influenciar na variação da dimensão dos elementos celulares. Bass (1973) afirma que o clima é um dos fatores que mais influencia a estrutura, tanto anatômica quanto morfológica das plantas, pode atuar em um curto espaço de tempo e no processo seletivo de evolução em um espaço mais longo, fixando então, geneticamente as características mais adaptadas.

Zimmermann \& Brown (1974) e Zimmermann (1983) afirmam que o sistema condutor é condicionado pela disponibilidade hídrica do ambiente, dessa forma ele permite a melhor condutividade possível (eficiência), sem risco de ocorrer embolia (segurança). A seiva sobe à medida que é estabelecido um gradiente de pressão da base para o ápice da planta, uma vez que os líquidos não sofrem expansão de volume. Se a pressão é excessivamente negativa, a água passa para o estado de vapor formando bolhas, que continuam a crescer, devido à difusão de outros gases como, $\mathrm{N}_{2}, \mathrm{O}_{2}$ e $\mathrm{CO}_{2}$, que estão dissolvidos na água e à expansão volumétrica a que todos os gases são suscetíveis. Quando há a formação de bolhas, a pressão xilemática sobe até quase entrar em equilíbrio com a pressão atmosférica, parando por completo, o transporte hídrico. Portanto, quanto maior o diâmetro dos elementos vasculares, maior a condutividade hidráulica e maior a eficiência na condução, por outro lado, mais suscetível para a formação de bolhas, que também, apresentam maior tamanho. Quanto maior o tamanho da bolha menor é a possibilidade dela voltar a se dissolver e, dessa forma, restabelecer a coluna d'água. Por outro lado, quanto menores os diâmetros dos elementos vasculares, maior é a resistência ao fluxo, maior é a adesão capilar da água às paredes celulares e, portanto, menor é a probabilidade de ocorrer o rompimento da coluna d'água e a formação de bolhas. Nos capilares mais finos, as bolhas são menores e mais fáceis de serem dissolvidas.

Dodd (1984), quando da avaliação do lenho de árvores de Acer pseudoplatanus L., relata uma diferença acentuada na dimensão das células dentro das camadas de crescimento, principalmente, no sentido radial. A área dos vasos, em secção transversal, atingiu o máximo no meio da camada de crescimento e reduziu ao final. Já no sentido axial, o menor diâmetro do elemento de vaso foi encontrado na base do caule e dos ramos.

Segundo Wilkes (1988), a variação no tamanho e na forma dos elementos celulares, no sentido axial, é aparentemente menos consistente do que no sentido radial do caule e, de acordo com Digby \& Wareing (1966), uma das causas que pode levar à variação longitudinal, como na freqüência de vasos, está relacionada à concentração de reguladores de crescimento, os quais têm importante participação na atividade cambial.

Silva (1992) avaliou a variação dimensional dos elementos xilemáticos de Sacoglottis guianensis Benth. e Andira parviflora Ducke. Nesse estudo o autor afirma que em ambas as espécies as fibras e elementos de vaso demonstraram tendências de variação no sentido medula para periferia e da base para o topo da árvore.

Urbinati et al. (2003) em estudo realizado com o objetivo de analisar a variação quantitativa de alguns elementos celulares constituintes do lenho, em diferentes alturas do caule de Terminalia ivorensis A. Chev., nos planos axial e radial, verificaram que, no sentido radial do caule, alguns elementos anatômicos apresentaram tendências de variação definidas e significativas estatisticamente, dentre elas são citadas, a freqüência, o diâmetro e o comprimento dos elementos de vaso, a freqüência de raios $/ \mathrm{mm}$ linear, o comprimento dos raios em número de células, o comprimento e a espessura da parede das fibras. Segundo os mesmos autores, os resultados observados devem-se, principalmente, à caracterização bem definida dos lenhos juvenil e adulto na madeira dessa espécie.

Além da importância anteriormente relatada, faz-se importante que os estudos desta categoria sejam realizados com espécies nativas, tornando assim, possível a obtenção de informações que forneçam subsídios para o aperfeiçoamento de planos de recuperação de florestas, além de contribuírem para a caracterização anatômica do lenho de diferentes espécies e diferentes famílias. Por isso Podocarpus lambertii Klotzsch ex Endl., popularmente conhecida como pinheiro-bravo, foi escolhida para a realização desse estudo, uma vez que é nativa da Floresta com Araucária e, segundo Inoue (1972), caracteriza-se por ocorrer sempre formando grandes populações e, de acordo com Reitz et al. (1983), é uma espécie de interesse na recuperação de áreas degradadas, pois diminui o impacto ambiental causado por fatores antropogênicos. Dessa forma o presente estudo teve 
como objetivo avaliar a variação dimensional das traqueídes ao longo do caule de Podocarpus lambertii Klotzsch ex Endl.

\section{Material e métodos}

O material estudado foi oriundo de uma região de várzea localizada em Araucária, município da Região Metropolitana de Curitiba, a aproximadamente $20 \mathrm{~km}$ da capital do Estado do Paraná, próxima às coordenadas $25^{\circ} 34^{\prime} 02,5^{\prime}$ 'S e $49^{\circ} 20^{\prime} 53,5^{\prime \prime} \mathrm{W}$ e em uma altitude de aproximadamente $900 \mathrm{~m}$ s.n.m.

As coletas de madeira realizadas ao longo do caule foram obtidas de três indivíduos com perímetro altura do peito (PAP) entre 7 e $8 \mathrm{~cm}$. Primeiramente foram retirados discos de madeira ao longo do caule, com aproximadamente $20 \mathrm{~cm}$ de espessura nas alturas, nível do solo, 1 metro e 2 metros do nível do solo. Para a análise da variação dimensional das traqueídes foram selecionadas, de cada um dos discos de madeira, por meio de incisões transversais e no sentido medulacâmbio sete amostras nos limites das camadas de crescimento. Essas amostras foram maceradas de acordo o método de Franklin (1946). A coloração foi feita com safranina $0,5 \%$ em solução álcoólica-etílica $50 \%$. Para o preparo das lâminas empregou-se como meio de montagem glicerina e esmalte incolor para a lutagem das mesmas.

A descrição da estrutura do lenho seguiu as orientações propostas pelo IAWA Committee (2004). As mensurações foram realizadas com o auxílio do software Image-Proplus em fotomicroscópio OlympusBX41 com captura de imagem. Foram realizadas para cada variável analisada, comprimento, diâmetro e espessura da parede celular das traqueídes, 50 medições em cada camada de crescimento, das quais foram calculados, a média, o desvio padrão e variância para todas as variáveis analisadas. A estatística descritiva foi realizada utilizando-se o programa Excel, da Microsoft (2000). Para o estudo estatístico dos resultados foi utilizado o programa Statistica for Windows da Stasoft, Inc. (1999).

Para todas as variáveis foi, primeiramente, verificado o padrão das distribuições por meio do teste Shapiro-Wilk. Em todas as análises foi aplicado o teste "t-student", para verificar se as medidas morfoanatômicas eram equivalentes entre as camadas de crescimento. A partir dos dados obtidos por meio da mensuração das traqueídes, foram testadas as hipóteses de que as médias nas diferentes alturas, assim como entre as camadas de crescimento são iguais.

\section{Resultados e discussão}

Descrição geral (macroscópica) - O aspecto geral de uma secção transversal do lenho de Podocarpus lambertii Klotzsch ex Endl. demonstra que a madeira é branco-amarelada, com alguns pontos, manchas escuras. É leve e macia, a grã é direita, a superfície é uniforme e a textura fina. $\mathrm{O}$ contraste gradual e suave entre as zonas de lenho inicial e tardio é formado, principalmente, pela diferença no espessamento das paredes celulares das traqueídes, no entanto, as camadas de crescimento são pouco evidentes. Não há distinção entre cerne e alburno.

As camadas de crescimento próximas à medula possuem maior largura do que aquelas localizadas próximo ao câmbio vascular. Esse mesmo aspecto foi relatado por Urbinati et al. (2003), apesar desses autores terem realizado com o xilema secundário de uma Magnoliophyta, ou seja, sobre a variação estrutural quantitativa no lenho de Terminalia ivorensis A. Chev. De acordo com Zobel \& Talbert (1984), as camadas de crescimento localizadas próximas à medula possuem características muito diferentes daquelas localizadas próximas ao câmbio vascular, pois as camadas perto da medula foram formadas num período em que o ritmo de crescimento é mais acentuado. As camadas localizadas próximas ao câmbio foram formadas durante o período de maturidade da árvore.

De acordo ainda com Kozlowsky \& Pallardy (1997), a largura das camadas de crescimento varia de uma fração de milímetros a até alguns centímetros, dependendo de muitos fatores ambientais, dentre eles, a disponibilidade hídrica. Larcher (2000) afirma que a duração da atividade cambial e o tipo de formação da madeira são afetados por fatores ambientais que podem exercer influências diretas ou indiretas sobre a largura e a aparência das camadas de crescimento. Dentre os vários fatores, esse autor, cita o suprimento hídrico e todos os tipos de injúrias causados pelo ambiente. Sob stress a divisão celular torna-se mais lenta, como conseqüência menos traqueídes são formadas e menor é a espessura da camada de crescimento.

Descrição microscópica - O conhecimento dos tipos celulares que constituem o lenho, assim como à sua organização e peculiaridades estruturais é de fundamental importância, pois permitem compreender o comportamento da estrutura anatômica durante os diferentes estágios de desenvolvimento de um indivíduo, assim como a interferência de fatores do ambiente. 
O lenho de Podocarpus lambertii Klotzsch ex Endl., em secção transversal revela que as camadas de crescimento apresentam-se distintas, pois o lenho inicial apresenta seus elementos com paredes celulares delgadas e lume grande, e é menos denso (Fig. 1, 2 e 3); já o lenho tardio tem suas células com paredes espessas e lume pequeno, sendo mais denso. As traqueídes são menos regulares, muito unidas e com o lume celular mais arredondado (Fig. 1, 2 e 4). As pontoações areoladas são freqüentemente observadas nas paredes radiais das traqueídes (Fig. 6). O parênquima axial é difuso (Fig. 1 e 8).

Em material dissociado, as traqueídes são longas, apresentando um comprimento aproximado de $2238 \mu \mathrm{m}$ $(1510$ a $2593 \mu \mathrm{m})$, diâmetro com cerca de $30 \mu \mathrm{m}(25,31$ a $32,32 \mu \mathrm{m})$ e espessura da parede celular de aproximadamente $5 \mathrm{~mm}(4,76$ a 5,22 $\mu \mathrm{m})$. De acordo com Rizzini (1995), as traqueídes possuem comprimentos que variam entre 1200-1800 $\mu \mathrm{m}$. Em árvore cultivada verificou-se que as traqueídes medem entre 1300-2800 $\mu \mathrm{m}$, sendo os mais freqüentes entre 1800-2500 $\mu \mathrm{m}$ e o predominante, $2500 \mu \mathrm{m}$.

Os raios são homogêneos, constituídos por células parenquimáticas de paredes finas (Fig. 5, 6 e 7) e unisseriados (Fig. 8). Nos campos de cruzamento ocorrem muitas pontoações, próximas entre si e do tipo piceóide (Fig. 7). Ainda é possível observar nas células de parênquima radial a presença de depósitos de resina.

Comprimento das traqueídes - Os resultados obtidos demonstram que os menores valores estão localizados próximos à medula. Na direção medula-câmbio observou-se um aumento e tendência à estabilização. As traqueídes próximas à medula diferiram estatisticamente daquelas localizadas próximas ao câmbio quanto ao comprimento. Essa diferença, no sentido medula-câmbio, foi significativa ao nível de 5\% de probabilidade (Tab. 1 e 2). Essa mesma tendência foi observada ao longo da árvore de Podocarpus lambertii Klotzsch ex Endl.

Os resultados obtidos foram semelhantes àqueles encontrados por Giroud (1977) e Foelkel et al. (1983). Fukazawa \& Ohtani (1982), estudando a variação anatômica em Tilia japonica (Miq.) Simonk., observaram que a $5,30 \mathrm{~m}$ de altura do caule o comprimento dos elementos vasculares aumentou no sentido medula-câmbio e, depois de alcançar valor máximo, estabilizou. Em outras alturas, a variação foi muito pequena. Por outro lado, Silva (1992) encontrou em Andira parvifolia Ducke. maior comprimento dos elementos vasculares nas proximidades da medula do que próximo ao câmbio. Iqbal \& Ghouse (1983) avaliaram a média do comprimento dos elementos de vaso em Prosopis spicigera L., encontrando aumento inicial a partir do câmbio em direção à medula, e declínio gradual, com algumas flutuações, próximo à medula. Urbinati et al. (2003) encontraram no lenho de Terminalia ivorensis A. Chev. a mesma tendência de variação encontrada no presente estudo.

De acordo com Silva (1992), a maioria dos trabalhos sobre variação quantitativa, no sentido radial, tem mostrado que o valor do comprimento celular no anel próximo à medula é pequeno, tanto para coníferas como para folhosas de florestas de clima temperado, porém aumenta rapidamente nos primeiros anéis e estabiliza após atingir um valor máximo. Jankowsky (1979) cita que a mais importante variação que ocorre durante o desenvolvimento do lenho é no comprimento das células, que aumentará em qualquer nível da árvore, a partir da medula até o fim dos sucessivos anéis de crescimento, alcançando um valor mais ou menos constante após um certo número de anos. O aumento no tamanho das células até que a árvore atinja a maturidade pode ser de três a quatro vezes o tamanho original para as coníferas.

Flörsheim \& Tomazello Filho (1996) e Flörsheim et al. (1999) na avaliação da variação das dimensões dos vasos no sentido medula-casca e base-topo de árvores de Myracrodruon urundeuva Allemão constataram que, no sentido longitudinal, os menores valores de comprimento dos vasos foram encontrados na base e os maiores a 50\% da altura; no sentido radial, os menores valores de comprimento de vasos foram encontrados na região próxima à medula. Klock et al. (2002) constataram que as traqueídes em Pinus maximinoi H.E. Moore apresentam a tendência de aumento rápido e acentuado do comprimento no sentido medula-casca.

Diâmetro das traqueídes - Esta característica tem sido pouco estudada quando comparada aos estudos sobre o comprimento dos mesmos. No entanto, Silva (1992) afirma que esta característica tem uma relação direta com uma das propriedades mais importantes da madeira, o peso específico.

Em relação ao diâmetro das traqueídes de Podocarpus lambertii Klotzsch ex Endl., os testes estatísticos demonstram que houve uma variação mínima entre as camadas de crescimento, poucas diferiram estatisticamente ao nível de $5 \%$ de probabilidade (Tab. 1 e 2). Essa mesma característica foi observada ao longo do caule. 

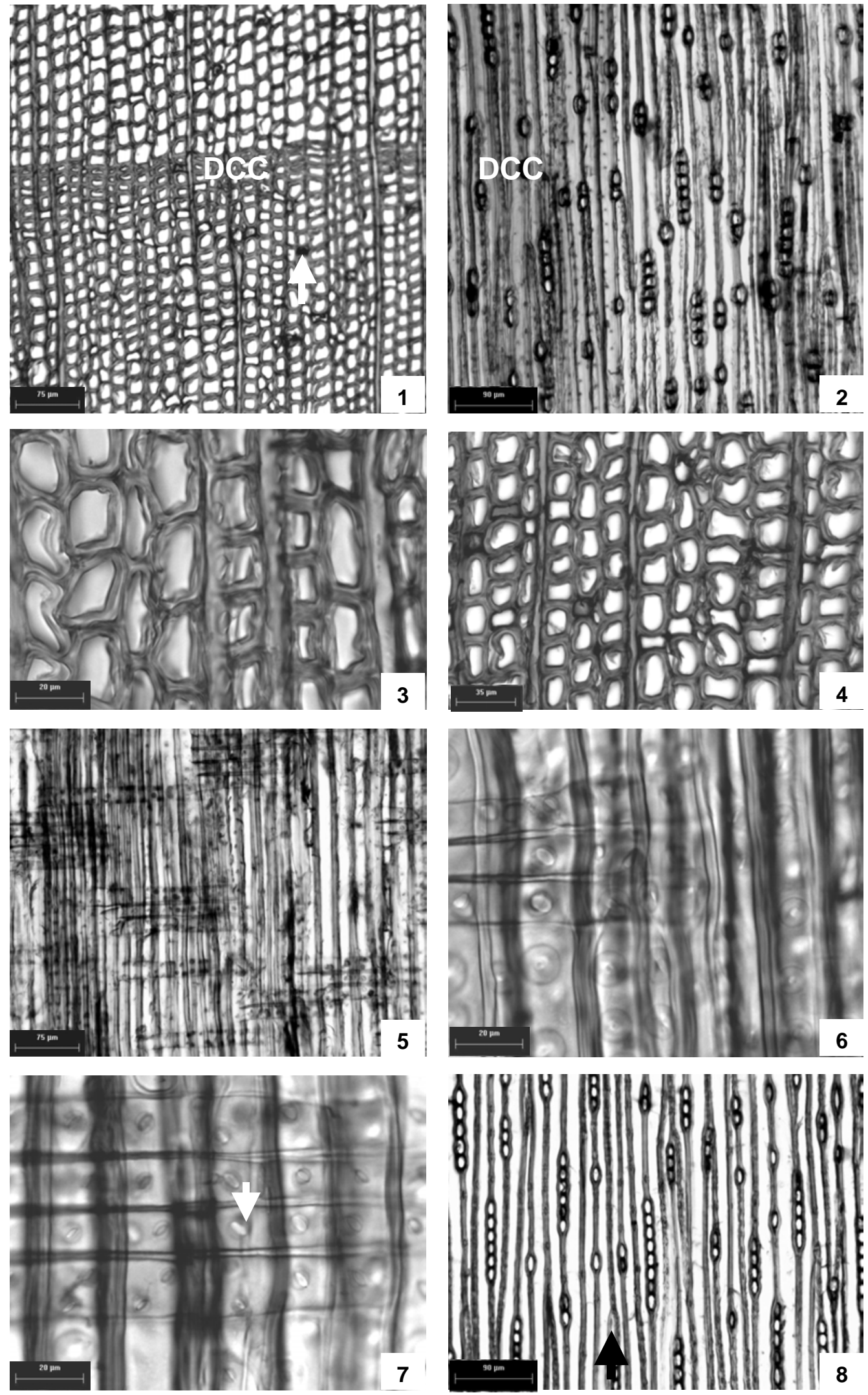

Figuras 1-8. Podocarpus lambertii Klotzsch ex Endl. 1. Secção tranversal. Delimitação da camada de crescimento (DCC), a seta ( $\uparrow$ ) indica o parênquima axial difuso. 2. Secção tangencial. Delimitação da camada de crescimento (DCC). 3. Secção transversal. Lenho inicial. 4. Secção transversal. Lenho tardio. 5. Secção radial. Raios homogêneos. 6. Secção radial. Pontoações nas paredes radiais. 7. Secção radial. Pontoações tipo piceóide $(\downarrow)$. 8. Secção tangencial. Parênquima axial difuso $(\uparrow)$ e raios homogêneos e unisseriados. 
Tabela 1. Média \pm desvio-padrão das dimensões das traqueídes nas camadas de crescimento e ao longo do caule Podocarpus lambertii Klotzsch ex Endl. $(\mathrm{n}=150)$.

\begin{tabular}{|c|c|c|c|c|c|c|c|c|c|}
\hline \multirow{3}{*}{ *Camadas } & \multicolumn{9}{|c|}{ Dimensões das traqueídes $(\mu \mathrm{m})$} \\
\hline & \multicolumn{3}{|c|}{ Comprimento } & \multicolumn{3}{|c|}{ Diâmetro } & \multicolumn{3}{|c|}{ Espessura da parede celular } \\
\hline & Base & $1 \mathrm{~m}$ & $2 \mathrm{~m}$ & Base & $1 \mathrm{~m}$ & $2 \mathrm{~m}$ & Base & $1 \mathrm{~m}$ & $2 \mathrm{~m}$ \\
\hline 1 & $1903,1 \pm 220,8$ & $1981,5 \pm 220,6$ & $2031,5 \pm 199,4$ & $27,2 \pm 5,1$ & $27,1 \pm 4,9$ & $25,0 \pm 4,3$ & $4,5 \pm 1,2$ & $4,9 \pm 1,2$ & $5,0 \pm 1,2$ \\
\hline 2 & $1881,8 \pm 221,9$ & $1955,6 \pm 147,6$ & $1945,8 \pm 187,1$ & $26,1 \pm 4,2$ & $26,8 \pm 5,0$ & $26,6 \pm 5,1$ & $4,6 \pm 0,9$ & $4,9 \pm 1,1$ & $4,9 \pm 1,1$ \\
\hline 3 & $1804,8 \pm 298,5$ & $1889,3 \pm 213,2$ & $1934,5 \pm 218,9$ & $26,8 \pm 5,0$ & $27,2 \pm 4,5$ & $27,8 \pm 5,0$ & $4,6 \pm 1,1$ & $4,8 \pm 1,0$ & $4,8 \pm 1,1$ \\
\hline 4 & $1859,6 \pm 260,4$ & $1946,5 \pm 312,0$ & $1776,0 \pm 265,3$ & $25,8 \pm 4,0$ & $26,1 \pm 5,3$ & $24,7 \pm 4,8$ & $4,6 \pm 1,0$ & $4,7 \pm 1,2$ & $4,7 \pm 1,1$ \\
\hline 5 & $1987,6 \pm 236,5$ & $1986,5 \pm 201,6$ & $1945,8 \pm 187,1$ & $25,3 \pm 4,2$ & $28,1 \pm 4,6$ & $24,4 \pm 4,3$ & $4,4 \pm 1,0$ & $4,9 \pm 1,1$ & $4,7 \pm 1,1$ \\
\hline 6 & $1802,3 \pm 285,8$ & $1749,0 \pm 236,1$ & $1934,5 \pm 218,9$ & $27,1 \pm 4,6$ & $28,1 \pm 4,4$ & $26,1 \pm 3,5$ & $4,6 \pm 1,1$ & $4,9 \pm 1,1$ & $5,0 \pm 1,0$ \\
\hline 7 & $1690,3 \pm 322,8$ & $1896,5 \pm 197,1$ & $1776,0 \pm 265,3$ & $24,3 \pm 4,7$ & $28,2 \pm 5,3$ & $23,0 \pm 4,0$ & $4,5 \pm 1,1$ & $4,9 \pm 1,1$ & $4,7 \pm 1,2$ \\
\hline
\end{tabular}

* Os números da coluna camadas referem-se às camadas de crescimento no sentido câmbio-medula. Base, $1 \mathrm{~m}$ e $2 \mathrm{~m}$ referem-se às coletas realizadas no nível do solo, a $1 \mathrm{~m}$ e $2 \mathrm{~m}$ do nível do solo, respectivamente.

A mesma tendência encontrada no presente estudo foi observada por Giroud (1977), Fukazawa \& Ohtani (1982), Bosman et al. (1994), Helinska (1995) e Urbinati et al. (2003). A distinção entre os lenhos juvenil e adulto pode, em algumas espécies, ser impossível de definir com base na largura dos elementos vasculares. Butterfield et al. (1993) não observaram variação no diâmetro dos elementos de vaso em Hieronyma alchorneoides Allemão e Vochysia guatemalensis Donn. Sm. Bosman et al. (1994), analisando a variação longitudinal em Shorea leprosula Miq., observaram que a média no diâmetro dos elementos vasculares também seguiu padrão pouco consistente, mas muitas árvores mostraram aumento a partir da base em direção ao ápice e somente duas das árvores analisadas apresentaram redução em torno de $10 \mathrm{~m}$ de altura do caule.

Flörsheim \& Tomazello Filho (1996) e Flörsheim et al. (1999) em estudo sobre o lenho de Myracrodruon urundeuva Allemão citam que os menores valores de diâmetro dos vasos foram encontrados na base e os maiores a $50 \%$ da altura, sendo que em direção à casca esses valores aumentam.

Jankowsky (1979) afirma que essas mudanças nas dimensões das células têm sido correlacionadas com as condições de desenvolvimento, sendo que as células menores e mais largas são formadas na parte inicial da estação de crescimento e que as células maiores e mais estreitas, na parte final da estação. Em certas folhosas tem sido observado que o diâmetro do vaso aumenta com o distanciamento da medula. As várias mudanças nas dimensões das células devem estar correlacionadas com mudanças correspondentes na organização da parede celular, onde a mudança mais importante está ligada ao ângulo de orientação das microfibrilas, na lamela secundária. Têm sido feitas referências ao fato de que em células curtas esse ângulo é grande e em células compridas ele é pequeno. Essas relações mantêm-se, tanto para coníferas como para folhosas, sendo observada uma mudança menor nas folhosas.

As pequenas diferenças encontradas nos diâmetros das traqueídes quando comparadas às camadas de crescimento, podem ser ainda explicadas ao considerar o que Larcher $(1995 ; 2000)$ expõe sobre "o caminho da água na planta". A maior velocidade do fluxo transpiracional depende da estrutura anatômica do tecido condutor. Em situações de aumento de tensão no sistema condutor, como por exemplo, dificuldade na absorção de água, a coesão da coluna de água pode ser rapidamente rompida. Com a quebra da coluna de água e a perda da pressão negativa dos vasos condutores ocorre entrada do ar no xilema (embolia), interrompendo no local, o fluxo transpiracional. O lenho que possui alta condutividade hidráulica específica no xilema é suscetível ao embolismo se comparado com elementos condutores com diâmetro pequeno no lume.

Espessura da parede celular das traqueídes - A análise da espessura da parede celular das traqueídes revelou que não houve variação entre as camadas de crescimento e nem ao longo do caule da árvore (Tab. 1-2). Flörsheim \& Tomazello Filho (1996) e Flörsheim et al. (1999) não observaram tendência definitiva para espessura da parede celular nos vasos de Myracrodruon urundeuva Allemão. Klock et al. (2002) observaram que a espessura das paredes celulares nas traqueídes de Pinus taeda L. é bem homogênea entre as camadas de crescimento. 
Tabela 2. Resultados do teste "t-student" quando comparadas às dimensões das traqueídes entre as camadas de crescimento e ao longo do caule Podocarpus lambertii Klotzsch ex Endl.

\begin{tabular}{|c|c|c|c|c|c|c|c|c|c|}
\hline \multirow{3}{*}{ *Camadas } & \multicolumn{9}{|c|}{ Níveis de significância entre as camadas de crescimento } \\
\hline & \multicolumn{3}{|c|}{ Comprimento } & \multicolumn{3}{|c|}{ Diâmetro } & \multicolumn{3}{|c|}{ Espessura da parede celular } \\
\hline & Base & $1 \mathrm{~m}$ & $2 \mathrm{~m}$ & Base & $1 \mathrm{~m}$ & $2 \mathrm{~m}$ & Base & $1 \mathrm{~m}$ & $2 \mathrm{~m}$ \\
\hline $1 / 2$ & 0,17 & 0,19 & 0,00 & 0,03 & 0,74 & 0,00 & 0,37 & 0,65 & 0,12 \\
\hline $1 / 3$ & 0,00 & 0,00 & 0,00 & 0,38 & 0,74 & 0,00 & 0,24 & 0,28 & 0,14 \\
\hline $1 / 4$ & 0,04 & 0,20 & 0,00 & 0,00 & 0,07 & 0,57 & 0,10 & 0,11 & 0,01 \\
\hline $1 / 5$ & 0,00 & 0,72 & 0,23 & 0,00 & 0,13 & 0,40 & 0,51 & 0,41 & 0,01 \\
\hline $1 / 6$ & 0,00 & 0,00 & 0,46 & 0,67 & 0,10 & 0,00 & 0,33 & 0,99 & 0,47 \\
\hline $1 / 7$ & 0,00 & 0,00 & 0,00 & 0,00 & 0,07 & 0,00 & 0,97 & 0,77 & 0,00 \\
\hline $2 / 3$ & 0,00 & 0,00 & 0,00 & 0,07 & 0,40 & 0,01 & 0,62 & 0,51 & 0,74 \\
\hline $2 / 4$ & 0,10 & 0,74 & 0,00 & 0,44 & 0,30 & 0,00 & 0,68 & 0,17 & 0,32 \\
\hline $2 / 5$ & 0,00 & 0,10 & 0,00 & 0,18 & 0,01 & 0,00 & 0,02 & 0,82 & 0,20 \\
\hline $2 / 6$ & 0,00 & 0,00 & 0,04 & 0,05 & 0,00 & 0,45 & 0,98 & 0,49 & 0,05 \\
\hline $2 / 7$ & 0,00 & 0,00 & 0,00 & 0,00 & 0,01 & 0,00 & 0,15 & 0,93 & 0,07 \\
\hline $3 / 4$ & 0,07 & 0,16 & 0,49 & 0,04 & 0,04 & 0,00 & 0,65 & 0,64 & 0,30 \\
\hline $3 / 5$ & 0,00 & 0,00 & 0,00 & 0,00 & 0,04 & 0,00 & 0,11 & 0,74 & 0,39 \\
\hline $3 / 6$ & 0,93 & 0,00 & 0,00 & 0,99 & 0,13 & 0,00 & 0,83 & 0,17 & 0,04 \\
\hline $3 / 7$ & 0,00 & 0,89 & 0,00 & 0,00 & 0,07 & 0,00 & 0,27 & 0,32 & 0,09 \\
\hline $4 / 5$ & 0,00 & 0,34 & 0,00 & 0,43 & 0,00 & 0,61 & 0,05 & 0,23 & 0,74 \\
\hline $4 / 6$ & 0,00 & 0,00 & 0,00 & 0,02 & 0,00 & 0,00 & 0,52 & 0,05 & 0,00 \\
\hline $4 / 7$ & 0,00 & 0,11 & 0,00 & 0,01 & 0,00 & 0,00 & 0,19 & 0,09 & 0,68 \\
\hline $5 / 6$ & 0,00 & 0,00 & 0,54 & 0,00 & 0,69 & 0,00 & 0,11 & 0,31 & 0,00 \\
\hline $5 / 7$ & 0,00 & 0,00 & 0,00 & 0,07 & 0,96 & 0,00 & 0,55 & 0,64 & 0,64 \\
\hline $6 / 7$ & 0,00 & 0,00 & 0,00 & 0,00 & 0,97 & 0,00 & 0,36 & 0,97 & 0,00 \\
\hline
\end{tabular}

* Os números da coluna camadas referem-se às comparações feitas entre as camadas de crescimento. Base, $1 \mathrm{~m}$ e $2 \mathrm{~m}$ referem-se às coletas realizadas no nível do solo, a $1 \mathrm{~m}$ e $2 \mathrm{~m}$ do nível do solo, respectivamente.

Halbwachs \& Wimmer (1987, apud Larcher 2000) e Wimmer \& Halbwachs (1992, apud Larcher 2000) relatam que alterações podem ocorrer no lenho de coníferas quando estas são expostas a diferentes tipos de estresse, comumente em plantas sob estas condições há uma diminuição da espessura e densidade da parede celular. Segundo Foelkel et al. (1975) e Larson et al. (2001), a espessura da parede celular aumenta no sentido radial do tronco, sendo este acréscimo mais pronunciado nas traqueídes do lenho tardio.

Os resultados observados no presente estudo podem estar relacionados com as flutuações no comprimento das iniciais cambiais, assim como o posicionamento das mesmas ao longo da árvore, pois em geral, as iniciais fusiformes aumentam em tamanho com a idade do meristema, porém, após alcançarem um valor máximo, tornam-se relativamente estáveis (Ghouse \& Yunus 1972; Ghouse \& Hashmi 1980). No caso de Podocarpus lambertii Klotzsch ex Endl. o comprimento das células inicialmente aumenta com a idade do câmbio e tende a estabilizar-se em um valor máximo acompanhando a idade deste meristema. A influência da altura na árvore sobre o comprimento das células xilemáticas tem sido observada em um bom número de espécies, no entanto, na espécie estudada não foi observada alteração neste valor ao longo do caule.

Com base nos resultados do presente trabalho pode-se concluir que, no sentido medula-câmbio, houve um aumento e tendência à estabilização no comprimento das traqueídes, uma variação muito pequena no diâmetro das mesmas e que não houve variação na espessura da parede celular das traqueídes. Essa mesma tendência foi observada ao longo do caule de Podocarpus lambertii Klotzsch ex Endl.

\section{Agradecimentos}

Agradecemos ao Centro Universitário Positivo (UnicenP), Mestrado em Gestão Ambiental e Curso de Ciências Biológicas e à Universidade Federal do Paraná, Departamento de Engenharia Florestal, Curitiba, Paraná, Brasil. 


\section{Referências bibliográficas}

Baas, P. 1973. The wood anatomical range in Ilex (Aquifoliaceae) and its ecological and phylogenetic significance. Blumea 21: 193-258.

Bosman, M.T.M.; Kort, I.; Genderen, M.K. Van \& Baas, P. 1994. Radial variation in wood properties of naturally and plantation grown light red meranti (Shorea sp., Dipterocarpaceae). IAWA Journal 15: 111-120.

Butterfield, R.P.; Crook, R.P.; Adans, R. \& Morris, R. 1993. Radial variation in wood specific gravity, fibre length and vessel area for two Central American hardwoods: Hyeronima alchorneoides and Vochysia guatemalensis: natural and plantation - grown trees. IAWA Journal 14: $153-161$.

Digby, J. \& Wareing, P.F. 1966. The relationship between endogenous hormone levels in the plant and seasonal aspects of cambial activity. Annals of Botany 120: 607-622.

Dodd, R.S. 1984. Radial and tangential diameter variation of wood cells within trees of Acer pseudoplatanus. IAWA Bulletin 5: 253-257.

Flörsheim, S.M.B. \& Tomazello Filho, M. 1996. Variação das dimensões celulares no sentido medula-casca e basetopo de árvores de aroeira Myracrodruon urundeuva F.F. \& M.F. Allemão (Anacardiaceae). Revista do Instituto Florestal 8(2): 153-65.

Flörsheim, S.M.B.; Tomazello Filho, M. \& Spegiorin, L. 1999. Variação das dimensões no sentido medula-casca e basetopo de árvores de aroeira Myracrodruon urundeuva F.F. \& A.F. Allemão (Anacardiaceae). Revista do Instituto Florestal 11(2): 159-71.

Foelkel, C.E.B.; Busnardo, C.A.; Dias, C.; Schmidt, C.; Silva, R.M.R. \& Vesz, J.B.V. 1983. Variabilidade radial da madeira de Eucalyptus saligna. Silvicultura 28: 726-731.

Foelkel, C.E.B.; Ferreira, M.; Nehring, J.H.; Rolim, M.B. 1975. Variabilidade no sentido radial de madeira de Pinus elliotii. Instituto de pesquisa e Ciências Florestais (IPEF) 10: 1-11.

Franklin, G.L. 1946. A rapid method of softering wood for microtome sectioning. Tropical Woods 88: 35 .

Fukazawa, K. \& Ohtani, J. 1982. Within a tree variation of wood element size in Tilia japonica. IAWA Bulletin 3: 201-205.

Ghouse, A.K.M. \& Hashmi, S. 1980. Changes in vascular cambium of Polyathia longifolia Benth et Hook in the relation to the girth of the tree. Flora (Jena) 170: 135-143.

Ghouse, A.K.M. \& Yunus, M. 1972. Some aspects of cambial development in the shoot of Dalbergia sissuo Roxb. Flora (Jena) 162: 549-558.

Giroud, B. 1977. Statistical analysis of wood structure variation as related to distance from the pith in Entandrophragma utile (Meliaceae). IAWA Bulletin 4: 71-75.

Helinska, R.L. 1995. Variation of vessel lumen diameter in radial direction as an indication of the juvenile wood growth in oak (Quercus petraea Liebl.). Forestry Abstracts 56: 610.
Iawa Committee. 2004. IAWA list of microscopic features for softwood identification. IAWA Bulletin 25(1): $1-70$.

Inoue, M.T. 1972. Estudo das coníferas potencialmente econômicas para o Brasil. Curitiba, Faculdade de Florestas - UFPR.

Iqbal, M. \& Ghouse, A.K.M. 1983. An analytical study on cell size variation in some arid zone trees of India: Acacia nilotica and Prosopis spicigera. IAWA Bulletin 4: 46-52.

Jankowsky, I.P. 1979. Madeira juvenil - formação e aproveitamento industrial. Instituto de pesquisa e Ciências Florestais (IPEF) 81: 1-15.

Klock, U.; Bolzon de Muñiz, G.I.; Nisgoski, S. \& Bittencourt, E. 2002. Características dos traqueóides da madeira juvenil de Pinus maximinoi H.E. Moore e de Pinus taeda L. Pp. 1-17. In: Congreso Iberoamericano de investigación en celulosa y papel.

Kozlowski, T.T. \& Pallardy, S.G. 1997. Physiology of woody plants. San Diego, Academic Press.

Larcher, W. 1995. Physiological plant ecology. $3^{\text {rd }}$ ed. New York, Springer-Verlag.

Larcher, W. 2000. Ecofisiologia Vegetal. São Carlos, Rima Artes e Textos.

Larson, P.R.; Kretschmann, D.E.; Clark III, A. \& Isebrands, J.G. 2001. Formation and Properties of Juvenile Wood in Southern Pines: a synopsis. General Technical Report. FPL-GTR-129. USDA. Forest Products laboratory. Madison.

Reitz, R.; Klein, R.M. \& Reis, A. 1983. Projeto madeira do Rio Grande do Sul. Sellowia 35(34/35): 1-525.

Rizzini, C.T. 1995. Árvores e madeiras úteis do Brasil manual de dendrologia. São Paulo, Edgard Blücher.

Sanio, K. 1872. Ueber die Grösse der Holzzellen bei der gemeinen Kiefer (Pinus sylvestris L.). Jahrbbusch Wissenschaftliche Botanik 8: 401-420.

Silva, C.A. 1992. Variação dimensional dos elementos xilemáticos em duas espécies madeireiras da Amazônia. Acta Amazonica 22: 261-274.

Urbinati, C.V.; Azevedo, A.A.; Monteiro da Silva, E.A. \& Lisboa, P.L.B. 2003. Variação estrutural quantitativa no lenho de Terminalia ivorensis A. Chev., Combretaceae. Acta Botanica Brasilica 17(3): 1-25.

Vysotskaya, L.G. \& Vaganov, E.A. 1989. Components of the variability of radial cell size in tree rings of conifers. IAWA Bulletin 10: 417-428.

Wilkes, J. 1988. Variations of wood anatomy within species of Eucalyptus. IAWA Bulletin 9: 13-23.

Zimmermann, M.H. \& Brown, C.L. 1974. Trees structure and function. $2^{\text {nd }}$ ed. New York, Springer Verlag.

Zimmermann, M.H. 1983. Xylem structure and the ascent of sap. Berlin, Springer Verlag.

Zobel, B. \& Talbert, J. 1984. Applied forest tree improvement. New York, John Wiley \& Sons. 